\title{
Youth-at-Risk to Kids at Hope: Flipping the Stereotype
}

\author{
Linda B. Pincham \\ Roosevelt University, USA
}

\begin{abstract}
Albert Einstein once said, "We cannot solve today's significant problems with the same level of thinking we were at when we created them." Educators, parents, and community members spend an exhaustive amount of time examining why children and youth fail, as opposed to why they succeed. More than often, these children and youth are stereotyped with the label of being "at risk" and are doomed for failure in schools and in their personal lives. Indeed, statistics support high numbers of school drop-out rates, gang affiliations, drug abuse, homelessness, teen pregnancies and school violence. These facts and data make it easier to be pessimistic about the future of many of our youth. However, research also documents that people succeed in life when there is a focus on their assets, not their liabilities. Kids at Hope is a different way of thinking. It focuses on seeing children as hope, not at risk. It is about helping children succeed. It is a cultural, strategic framework designed to engage entire communities-educators, parents, community members-to support the belief that all children are capable of success-no exceptions. This paper will outline a research and evidence-based protocol on the three leading principals or universal truths that is the foundation of Kids of Hope.
\end{abstract}

\section{Introduction}

There are several definitions for "at risk" in children and youth. The National Center for School Engagement (NCSE) has a more pragmatic definition: "The term at-risk youth typically implies a future with less than optimal outcomes." [1] NCSE provided a list of typical examples that most people associate with atrisk behaviors or situations in youth: homelessness; drug and alcohol use; sexual, physical, and/or emotional abuse; neglectful, abusive, or stressful home environments; a lack of social or emotional supports; and involvement with delinquent peers. Just one or a combination of these situations could put a child at risk for failure.

One cannot hide the horrendous conditions that so many of our youth face. According to the Annie E. Casey Foundation Kids Count Data Book 2011(also documented in Miller, 2012), there are several reality checks that detail about our children and youth in the United States [2]:
- More than one in eight preschool children lives with a parent or guardian who abuses or is dependent on alcohol or other drugs.

- African-American teens are almost twice as likely as White teens to be arrested for drug offense and more than five times likely to be incarcerated for drug offenses.

- Forty-six percent of African-American high school students, $39 \%$ of Latino and $11 \%$ of White students attend the 2,000 "dropout factories" across the United States, where less than $60 \%$ of the freshman class graduates in four years with a regular diploma.

- 1,741,379 children were arrested in 2008 .

- The United States has the highest teen birth rate among comparable countries.

- 2.9 million children live in families without secure parental employment.

To say the least, these conditions that many of our youth face are indeed harsh and are bound to promote negative psychological effects. However, if youth are consistently labelled as at-risk for conditions that are sometimes out of their control, they will begin to believe they are hopeless and worthless. They will acknowledge and accept the negative behaviors because they believe that is the expectation - that is their reality. They eventually fall into the trap of a stereotype threat. A stereotype threat is a socialpsychological concept in which people are or feel themselves to be at risk of conforming to stereotypes about their social group [3]. Youth who are identified as at-risk live with a social stigma that could follow them for life. They often affirm and internalize this label.

Fortunately, to balance the research on at-risk behaviors, there is equal research on hope and resiliency in youth. There are indeed children who live in the worst situations and are exposed to negative conditions that offer them a high risk for later problems and grim futures; yet, they somehow overcome those adversities and achieve promising developmental outcomes. Therefore, a question worth asking is "Why do some children succeed in spite of all the odds against them?" Studies on resilience all tend to have common factors: effective parents and caregivers, connections to other competent and caring adults, problem-solving skills, positive beliefs about the self, and effective teachers and schools, to name a few. [4] There is also a common thread in these factors: the need for caring adults. 
Rick Miller, the founder of Kids at Hope, noted that "understanding why some children do well and others struggle cannot come from conventional means." [4]. He proposed challenging conventional methods, like prevention programs and/or intervention programs, used to support youth. Instead, through his research, his plan was to shift thinking is a strategic cultural framework. As a result, Kids at Hope was created.

Kids at Hope (KAH) is a strategic, cultural framework designed to engage entire communities to support success for all children-no exceptions. It is a paradigm shift in thinking that moves away from the stereotyping label of "kids at risk" to "kids at hope." The goal of KAH is to create generations of adults and institutions who are committed to adopt this research and evidence-based protocol and strategic, cultural framework. There are three leading principles and/or practices that build the foundation of KAH: (1) We believe that all children are capable of success, no exceptions; (2) We connect with all children in a meaningful, sustainable way; and (3) We time travel or teach children to mentally time travel to their future in four destinations: home and family, career and education, hobbies and recreation, and community and service.

\section{Culture vs. Bureaucracy}

Culture and bureaucracy are two opposing forces that can determine the fate of an organization. One can compare the culture of an organization to the "human element" and the bureaucracy as the "systems element" or the efficiency side. The bureaucracy side is managed, and there is typically an adopted mission that is created by a few people, more than likely the leaders. Most people in the organization would not be able to articulate the mission itself or what it even means. In a bureaucracy, the level of commitment from the staff is formal, and the driving force is "have to". Culture, on the other hand, is about effectiveness. It is lead, not managed. Culture is based on a shared belief that is well-known by everyone and can be clearly articulated by all. There is a genuine commitment from the staff with an "above and beyond" mentality. Standards are high; the drive is "want to". The goal is to be great. Although culture and bureaucracy are two opposing forces, both are needed to make a successful operation.

Kids at Hope is about creating a positive and nurturing culture in an organization, not implementing a program. Programs, either prevention or intervention, tend to come and go, depending on their effectiveness. They tend to focus on the problem(s) at hand, which may or may not return. For example, if a middle school is experiencing bullying among their students, the school might implement a bullying program. It could work, or it could end the first year of implementation. As Miller states,
"Children do not grow up in programs or institutions; they are the sum total of all their experiences. Children grow up holistically. They grow up in cultures" [4]. It is easy to create programs to try to "fix" a problem. However, creating a positive culture in an organization changes mindsets and beliefs. It is more challenging.

To begin creating a culture in an organization, there must be a shared belief and a belief statement. A mission statement establishes the reason for an organization's existence. A shared belief, being both personal and shared, empowers the mindset of an organization of being stronger, more able, and more effective together than alone.

\section{Universal Truths}

KAH conducted a review of literature on teacher expectation on student learning and behaviors. During that investigation, the primary research question was "Why do some children succeed and others fail?" There were recurring themes that were consistent in the literature. The most prominent of those themes included [5]:

- Children who succeed seem to do so when they have people in their lives who believe they can succeed.

- Children who succeed have meaningful relationships with caring adults. (Children who fail are disconnected from those meaningful relationships and grow up in our institutions, programs, services and activities anonymously).

- Children who succeed have multiple goals and an understanding that their futures must include contributions made at Home and Family; Education and Career; Community and Service; and Hobbies and Recreation.

- Children who succeed are offered greater opportunities to develop their strengths rather than to correct their weaknesses.

- Children who succeed are nurtured by a culture that is focused on success and strengths.

These specific findings formed the basis for KAH's universal truths because they apply to all children and youth.

\subsection{Universal Truth 1: "We Believe"}

KAH's Universal Truth 1: "We Believe" is the first building block in building a culture of a shared belief. It states that "Children succeed when they are surrounded by adults who believe they can succeed." An organization that articulates and commit to that belief is with the phrase that "All children are capable of success, no exceptions." Universal Truth 1 is also known as the Pygmalion Effect or self-fulfilling prophecy. There is continued research that suggests that the expectations a teacher sets for an individual 
student can significantly affect the student's performance and/or behavior. For example, if a teacher sends messages or signals that her students are capable of achieving, the students tend to believe it. On the other hand, if the signals are negative and condescending, the students will behave or achieve accordingly.

To investigate whether adults who work with children believe in them, KAH created and issued an 11-question survey called Culture Scan. The purpose of the survey is to "identify beliefs as well as practices of individuals and organizations who share the responsibility for children's education, social, and emotional welfare and measure those beliefs and practices against research findings" [4]. The scan is based on a Likert Scale beginning with " 1 " (strongly agree) to "10" (strongly disagree). The following describes a few of the findings based on 800 responses [6]:

- $53 \%$ believe all children can succeed no matter what

- $13 \%$ believe their colleagues also believe all children can succeed no matter what

- $5 \%$ believe parents and the community believe all children can succeed no matter what

- $50 \%$ believe it's a school priority that children have a meaningful relationship on campus with an adult

- $29 \%$ believe their students are hopeful and excited about their future

- $38 \%$ believe that $80 \%$ of their students will succeed as an adult

The data shows that many adults who work with children find it difficult to believe that all children are capable of success, no exceptions. When interviews were conducted, many of the adults referenced the "reality" of too many children not succeeding because of their given risk factors. Unconsciously, these adults are conceding to the belief that children cannot and will not succeed because of at risk factors. To circle a 10 (strongly agree) on the scan showed a very different kind of adult - probably one who is willing to adopt the belief that all children are capable of success, not exceptions. This is a cultural commitment.

A 2014 Gallup Student Poll, which surveyed grades 5-12 nationally, identified what children and youth are saying [7]:

- Only 53\% identify themselves as being hopeful

- Only 54\% identify themselves as being engaged

- Only $64 \%$ are identified as thriving

- $14 \%$ identify themselves as discouraged

- $19 \%$ are actively disengaged

- $2 \%$ are identified as suffering

Hope, engagement, and well-being are the strongest indicators of student success, according to the results of this poll. As a result, KAH created the following definitions for hope, engagement, and well- being to be in alignment with a culture and belief system that is positive and nurturing [6]:

(1) Hope - ideas and energy we have for the future

(2) Engagement - involvement in and enthusiasm for school

(3) Well Being - how we think about and experience out lives

KAH strives to build a cultural commitment that requires a world where every child is surrounded by adults who totally believes in all of them and are fully committed to finding ways for all children to succeed, no exceptions.

\subsection{Universal Truth \#2: "We Connect"}

Universal Truth 2 states that "Children succeed when they have meaning, sustainable relationships with caring adults." Universal Truth 2 is all about the significance and importance children connecting with adults. Shapiro, et al quoted in Invincible Kids, "Locate a resilient kid and you will find a caring adult, or several who have guided him" [8].

$\mathrm{KAH}$ identifies four relationships or components for children and youth to feel valued, competent, and capable of success: anchor parents, other caring adults, high expectations, and opportunities to succeed.

The anchor parent is the most obvious relationship that holds the unconditional love. Other caring adults could include relatives, teachers, and any others who possess a strong protective factor toward the child. Children tend to not want to disappoint the adults in their lives who are concerned about their well-being; they typically want to please them. Adults who are defined by high expectations judge children by their potential, not by their behavior. They believe in children more than the children believe in themselves. Finally, there are those adults who find opportunities for children to experience and succeed.

KAH builds a culture of tracking students' relationships through the metaphor of Aces: the Ace of Hearts, the Ace of Clubs, the Ace of Spades, and the Ace of Diamonds [13]:

- The Ace of Hearts represents the anchor parent. The adult is responsible for the child's physical and emotional well-being 24 hours a day. This Ace must be given in unconditional love.

- The Ace of Clubs represents other caring adults. The adult can describe at least three very positive characteristics or skills or talents the child possesses. The child is very comfortable asking for this adult's assistance.

- The Ace of Spades points upward as a symbol for high expectations. The "spade" is associated with a "shovel" that can uncover the hidden treasures in children. This adult believes in the child more than the child believes in him/her self. This adult is often the "go-to" person to discuss a problem/concern beyond an academic issue. This 
adult is also able to judge the child by his/her potential, not just by his/her behavior.

- The Ace of Diamonds represents opportunities to succeed. Successful experiences are made up of the sense to belong, competency, usefulness/value, and empowerment. This adult often gives the child appropriate tasks and acknowledges his/her successes. The child has a strong sense of achievement and feels valued and appreciated in the adult's presence. The child succeeds in the adults' classroom or program/organization by sensing that he/she belongs, or feels competent, valued, useful; and recognizes that his/her achievement offer personal empowerment.

The following is an example of an "Ace" story, written by a classroom teacher who practices KAH. It illustrates how building relationships with students can have an everlasting affect:

About six years ago, I had a freshmen student named Dwayne. Dwayne didn't care about school or World Studies. He would pay attention here and there to topics he liked, but in general he just coasted by. Although I have a hard time remembering what he was like when he was a student in my class, it's the years after I remember.

Dwayne came back to my room for the next two years, his sophomore and junior year, during passing periods or lunch to talk. The first time he said, "I don't remember anything form your class except that video about weapons from WWI." Then there'd be a little bit of small talk and he'd be on his way. For those two years I thought to myself, "Great! He doesn't even remember a lesson I prepared, he just remembers a History Channel video clip." He would tell me how he still doesn't pay attention, doesn't like school, and doesn't like his teachers. I would encourage him to try his best and tell him he was capable of success, but it wasn't more than a few sentences here and there in the halls.

When Dwayne was a senior, he came to my room for the first time during class. I was in the middle of teaching and Dwayne stormed in and sat down. I got my class working on something and walked over to see what was his problem. Dwayne was sweating, furious, and, swears started pouring out of his mouth. I moved the conversation to the hallway and listened to everything he had to say. He explained how he felt all of the teachers were against him and how a student got in his face. He felt like enough was enough and he was about to punch the student, but he walked out instead and came to my room. I'm sure Dwayne expected me to scold him for yelling at another student, swearing, walking out of a teacher's room, and interrupting my class. Instead, I praised him for making the right decision, to walk away instead of getting into a physical altercation. I asked him what he wanted to do in the future, and he said he wanted to join the National Guard and go to college. We talked about how he could use this for motivation to avoid fighting and that he could come talk to me any time.

As the year went by, Dwayne visited my room instead of fighting once a week on average. Each time he came to my room, I reminded him about his possibilities for his future and how fighting would put a stop to those plans. On the day of his graduation he came up to me after the ceremony and gave me a huge hug and a large grin. He said, "You're right! I made it! No fights!" I honestly didn't realize the impact I had on him until that moment. All of the days he came into my room I was so tense and worried about taking care of my class, taking care of Dwayne, not upsetting the teacher whose room he was supposed to be in, etc. that I hadn't really realized how much I helped him.

Dwayne has come back to visit me every year. He is in the National Guard and just started taking college courses this year. He always thanks me for being a place he could go when he was upset and getting him out of Chicago. $\mathrm{He}$ is my biggest and most memorable Ace. I'm not sure I taught him anything about history, but I did give him a safe space to go, someone to talk to, and encouragement to succeed.

Schools and/or organizations that practice $\mathrm{KAH}$ track the types of relationships or Aces children do or do not have. Their belief system is a commitment to ensure that all children have a meaningful and sustainable relationship with caring adults because they understand that children need Aces to succeed.

\subsection{Universal Truth \#3: "Mental Time Travel"}

Universal Truth 3 states that "Children succeed when they can articulate their future." There are varied definitions of the word "success." In order to support any student's success, adults in an organization need to have a shared definition. Hence, KAH conducted a research where successful people were asked to give examples of their successes. The results showed that success was defined in personal terms or connected to some type of contribution. As a result, there were four areas in which KAH labels as destinations: home and family, hobbies and recreation, education and career, and community and service. Therefore, $\mathrm{KAH}$ views success as not a thing but a place - these four destinations in which students strive to contribute. So, cultural success, according to $\mathrm{KAH}$, is achieved as a direct result of knowing you contributed to each of life's four destinations.

In the KAH cultural framework, the term "future" is multidimensional. The shared goal is to provide children and youth with the tools to navigate their lives to the four destinations. Adults can help children and youth see their future by helping them developing a plan to get there and helping them find the energy to pursue their goals. 
Miller posits that "the notion of future generates the concept of hope" [4]. He outlines in his book Youth Development the work of C.R. Snyder and Shane Lopez as contributing to his understanding of the concept of hope. Snyder [9] defined hope as the "overall perception that one's goals can be met" and it has three necessary ingredients: (1) Goal-oriented thoughts - These goals can be either short-term or long-term; (2) Goals need to be of sufficient value to the individual so as to occupy conscious thought.; and (3) Goals should be attainable yet challenging in nature.

Hope is a learned skill. It can be taught, planned for, and assistance can be given. Caring adults teach children this skill. KAH coins those adults as "hopeologists."

The three universal truths discussed create the cultural framework of KAH. When they are in place in an organization, a culture of hopefulness is created.

\section{Caring Adults as Treasure Hunters}

One is given a title or position in a bureaucracy - a job title that defines certain tasks and responsibilities associated with the position. In a KAH culture, the title is Treasure Hunter. It is a title in which one chooses to accept; it defines who you are rather than what you do, as in a bureaucracy. KAH defines treasure hunter as "a caring adult who searches beneath the surface to find all the talents, skills, and intelligence that exist in children". The title of treasure hunter is a cultural title because it is shared; it is critical in defining culture. All treasure hunters, for example, share the same responsibilities [4]:

(1) they all believe that all children are capable of success, no exceptions; (2) they all ensure that children have meaningful, sustainable relationships with caring adults; (3) they are all committed to teaching children the power to mentally time travel to four destinations: home and family, education and career, community and service, and hobbies and recreation; and they all are committed to the Treasure Hunter's Pledge:

As an adult and a treasure hunter, I am committed to searching for all the talents, skills, and intelligence that exist in children. I believe that all children are capable of success, no exceptions!

The Treasure Hunter's Pledge is a commitment to children and youth. When this practice is adopted, the entire organization's culture changes.

\section{The Kids at Hope Pledge: Promoting Positive Thinking}

There is power in positive thinking. Practicing positive thinking on a daily basis can make one feel more positive about oneself; it boosts confidence and builds self-esteem; and it makes one feel as if he/she is in control. Seligman [10] in his book Learned Optimism, stated that "Our thoughts are not merely reactions to events; they change what ensues." KAH promotes the practice of positive thinking by encouraging children and youth to recite the following pledge each day:

- I am a Kid at Hope

- I am talented, smart, and capable of success

- I have dreams for the future, and I will climb to reach those goals and dreams every day.

- All kids are capable of success--no exceptions!

Similar to the Treasure Hunter's Pledge where the adult makes the commitment to the child, the Kids at Hope Pledge is about the child making a pledge to themselves. It is an affirmation and positive thinking. By repeating this pledge on a daily basis, they will assume it; they will become it.

\section{Flipping the "Kids at Risk" Paradigm}

As stressed throughout this paper, the overall goal of $\mathrm{KAH}$ is to create generations of adults and institutions to commit to the belief that all children are capable of success, no exceptions. Imagine the power of this thinking and how it could impact our children's future. What would it look like? What do schools and various organizations do to empower children and youth through practicing KAH's three universal truths?

The following outlines what ten schools and community organizations in the United States have done to flip the "kids at risk" paradigm [6]:

- Annapolis, Maryland - A Director of Youth and Community Affairs in the mayor's office with two other community members received $\mathrm{KAH}$ training. After the training they held a public Kids at Hope presentation at City Hall, which was attended by educators, city council members, parents, and other community members. Annapolis later identified a population of Treasure Hunters who moved throughout the communities. Finally, they planned a Hopeology Day to bring the KAH model to a coalition of churches that are working with Latino and African-American youth.

- Albion, Michigan - The KAH model was implemented in the Albion School District. Throughout the schools' hallways are KAH banners and displays; students recite the KAH pledge daily. A local Boy Scout Troup also adopted the KAH model. A pastor from a local church donated 10.000 square feet of space for after school programming that implemented the Kids at Hope model. Activities range from recreation to life skills.

- St. Lucie County, Florida - St. Lucie County had an issue with gang activity. Community leaders were in the process of creating a gang prevention strategy when they heard about Kids at Hope. When they asked gang members why they joined 
gangs, an absence of hope was typically a top response. A community roundtable was formed where each member read a copy of Miller's Youth in the Trenches. More than 400 individuals who represented schools, youth and faith-based organizations, and law enforcement received KAH training (2008). The community roundtable even revised their vision statement to "We envision a community of opportunity where every child succeeds." The KAH model was also adopted at the Community Center-children who attend the center recite the pledge. Finally, the Children's Service Council of St. Lucie County trained the 30-40 agencies they fund.

- Lakewood, Washington $-\mathrm{As}$ a result of a $\$ 10$ million gift for the building of a Boys and Girls Club, donated by local philanthropists, Gary and Carol Milgard, the Lakewood Hope Square Campus that included the Gary and Carol Milgard Hope Center, as well as a new school that was renamed Lakeview Hope Academy were constructed. Each organization maintains its own mission but all share the Kids at Hope belief system that all kids are capable of success, no exceptions. All of the teachers and staff at Lakeview Hope Academy received KAH training. More than 800 people (teachers, school bus drivers, nurses, kitchen helpers, youth service workers) in the Hope Center were trained as well so that everyone could hear the same language of $\mathrm{KAH}$.

- Avondale, Arizona - The Avondale community has branded itself as one which has adopted $\mathrm{KAH}$; they celebrate National Kids at Hope Day/Week consistently. The community also sponsors at least one 4-hour seminar a year for all interested adults in the community to learn about $\mathrm{KAH}$, its principles and practices, and how that information can empower each adult to help all children succeed. They also sponsor at least one 2-day Train the Trainer Certification Academy annually.

- Hortonville, Wisconsin - Hortonville Elementary and Middle Schools created a monthly Family Day, where one of the activities centers around one of the four destination points. A Destination Day was also held during which community members came and talked about one of the destination points. For example, a chiropractor spoke about his career; an owner of a Karate America did a demonstration; a parent volunteer talked about raising money for troops overseas; and a Latino parent shared family traditions.

- Indio, California - The City of Indio Youth Center adopted the KAH cultural framework. The Human Services Department hosted a Kids at Hope workshop for 40 people, representing local schools, Big Brothers, Big Sisters, Boys and Girls Clubs, and law enforcement and faith-based organizations. Since the Center's opening in
2008, all staff members wear neck lanyards that have the KAH logo; throughout the facility is $\mathrm{KAH}$ signage. At the staff meetings (before the center opens), the director reminds the staff that they are a Kids at Hope center to keep them grounded in their belief.

- Vallejo, California - The principal at Widenmann Elementary School implements the KAH model despite the challenges of staffing changes, a transient student population, and having decisions made by the state. The students in her school recite the $\mathrm{KAH}$ pledge daily; however, the students added an additional line of their own - at the end of the pledge, they say "I am capable of success!" In the after-school program, the teachers have a Vision Board. The students are encouraged to write or draw what they want their future to look like and how they plan to achieve it. (mental time travel)

- Phoenix, Arizona - The Pendergast School District was the first in the nation to adopt Kids at hope. Student feedback was quite telling. Students said that before KAH was implemented, they did not feel valued in the school and felt like the teachers did not have faith in them. The Mesa YMCA was the first community center in the nation to apply the Little Kids at Hope model, designed for children five years old and younger.

- Springfield, IL - Funded through the National Recreation Foundation, Springfield became a $\mathrm{KAH}$ pilot project (Kids at Hope Springfield). The pilot was so successful that a five-year, $\$ 300,000$ challenge grant was awarded to support the creation of 15 Kids at Hope Square communities.

\section{Conclusion}

Kids at Hope was founded in 1993 by Rick Miller as a strategic effort to "flip" the stereotype of "at risk," a term historically used to marginalize and label children and youth who are confronted by situations that doom them for failure in their personal lives and in school. As Miller states, "The 'at-risk' stereotype has prematurely judged our youth guilty until proven innocent" [4]. KAH is a belief system that builds on the principle that "all children are capable of success, no exceptions". It is a powerful cultural, strategic framework designed to reach all communities that are involved in children's lives. Since 2005, over 12,000 individuals have been trained in $\mathrm{KAH}$ [6] and are using its belief system to positively promote the strengths of children and youth, not their weaknesses. The practices of KAH positively and intentionally impact the lives of children and youth with a very strong message of hope, success, and optimism. 


\section{References}

[1] National Center for School Engagement (NCSE): Promoting attendance, attachment, and achievement. Retrieved February 25, 2017. http://schoolengagement.org /school-engagement-services/at-risk-youth. (Access Date: 25 February, 2017)

[2] Annie E. Casey, Foundation KIDS COUNT Data Center. (2011). Indicator Name. Retrieved from datacenter.kidscount.org. and also found in Miller, Rick (2012). Miller, Rick (2012). Youth development from the trenches, pp. xii-xiii.

[3] Steele, C.M. and Aronson, J. (1995). "Stereotype threat and the intellectual test performance of African-Americans. Journal of Personality and Social Psychology, 69, pp. 797811.

[4] Miller, R., (2012). Youth development from the trenches, pp. xvi.

[5] "The science behind Kids at Hope," Newsvision, Kids at Hope, 2009, p.49

[6] Newsvision, Kids at Hope, 2009, pp. 5, 9, 10, 13, 17, $22,25,31,32-33,34$.

[7] 2014 Gallop Student Poll, Kids at Hope University, Module I, p. 23.

[8] Shapiro, J., D. Friedman, M. Meyer, \& M. Loftus. 1996. "Invincible kids." U.S. News \& World Report, (19): 62-70.

[9] Snyder, C.R., (2000). "The past and possible future of hope". Journal of Social and Clinical Psychology, 19, pp. $11-28$.

[10] Seligman, M., (1990). Learned optimism. New York: AA Knopf. 